\title{
As práticas de gestão de pessoas nas empresas de economia de comunhão: estudo de caso no Polo Spartaco
}

\author{
People management practices in companies of economy of communion: a case study in \\ Polo Spartaco
}

\author{
Maria Célia Vieira Ladain ${ }^{1}$ \\ Isabel de Sá Affonso da Costa ${ }^{2}$ \\ Denise Medeiros Ribeiro Salles ${ }^{3}$
}

\section{Resumo}

Para que uma firma seja considerada empresa de economia de comunhão (EEdC), ela deve seguir princípios específicos, fundamentados nos valores da cultura da partilha, expressos na Carta de Princípios da Empresa de Economia de Comunhão (EdC). Este estudo teve por objetivo verificar se as empresas do Polo Spartaco coadunam os princípios expostos nessa carta, na prática cotidiana da gestão de pessoas, por meio de um estudo de caso descritivo, com abordagem qualiquantitativa, utilizando-se de entrevistas semiestruturadas com os gestores, aplicação de questionário aos funcionários, observação direta e evidências documentais. Os resultados apontam que as práticas de gestão de pessoas das empresas vinculadas ao Polo Spartaco, de fato, coadunam o discurso expresso na Carta de Princípios da EdC. Observou-se que suas práticas de gestão de pessoas, ainda que de forma pouco estruturada, são bem-sucedidas para gerar produtividade, engajamento, participação e consolidação de valores.

Palavras-chave: Economia de comunhão. Gestão de pessoas. Recursos Humanos. Cultura da partilha.

\begin{abstract}
To be regarded as a company of economy of communion (EEdC), a firm should follow specific principles, grounded on the values of the sharing culture, expressed in the Charter of Principles of the Company of Economy of Communion $(E d C)$. This study aimed at verifying whether the companies of Polo Spartaco corroborate the principles expressed in this charter, in the daily practice of people management, through a descriptive case study, with a qualiquantitative approach, using semi-structured interviews with managers, application of a questionnaire to employees, direct observation, and documentary evidence. The results point out that the people management practices at the companies connected to Polo Spartaco, in fact, corroborate the discourse expressed in the Charter of Principles of EdC. It was observed that their
\end{abstract}

\footnotetext{
Artigo submetido em 01 de novembro de 2012 e aceito para publicação em 14 de dezembro de 2012.

${ }^{1}$ Mestre em Administração e Desenvolvimento Empresarial pela Universidade Estácio de Sá (MADE/UNESA). Endereço: Av. Pres. Vargas, 642/ $22^{\circ}$ andar, Centro, CEP 20071-001, Rio de Janeiro - RJ, Brasil. E-mail: mariaceliarh@hotmail.com

2 Doutora em Administração pela Escola Brasileira de Administração Pública e de Empresas da Fundação Getulio Vargas (EBAPE/FGV); Professora do Programa de Mestrado em Administração e Desenvolvimento Empresarial da Universidade Estácio de Sá (MADE/UNESA). Endereço: Av. Pres. Vargas, 642/ 22 andar, Centro, CEP 20071-001, Rio de Janeiro - RJ, Brasil. E-mail: isabel.costa@estacio.br

3

Doutora em Administração pela Escola Brasileira de Administração Pública e de Empresas da Fundação Getulio Vargas (EBAPE/FGV); Professora do Programa de Mestrado em Administração da Universidade Federal Fluminense (PPGAd/UFF). Endereço: Av. Pres. Vargas, 642/ $22^{\circ}$ andar, Centro, CEP 20071-001, Rio de Janeiro - RJ, Brasil. Email: denisesalles@id.uff.br
} 
people management practices, albeit poorly structured, are successful in generating productivity, commitment, participation, and consolidation of values.

Keywords: Economy of communion. People management. Human Resources Management. Sharing culture.

\section{Introdução}

A Economia de Comunhão (EdC) é um projeto econômico e empresarial surgido em 1991, em um movimento ligado à Igreja Católica - o Movimento dos Focolares. A EdC foi a resposta de um grupo de pessoas mobilizadas para intervir na economia capitalista, a fim de solucionar o passivo deixado pelo sistema econômico vigente - notadamente, o combate à pobreza, à exclusão e à miséria com uma inclusão dupla: comunitária e produtiva (EDC, 2012)

Na EdC, a cultura da partilha se contrapõe ao individualismo e à competição, estruturando-se sobre relações baseadas em princípios de amor, solidariedade, gratuidade e unidade em busca da consolidação dos bens relacionais ${ }^{4}$ capazes de suportar as fragilidades do sistema econômico dominante. É nesse contexto que a EdC contribui com seu modus operandi pautado no respeito ao ser humano, colocando-o como centro da empresa. As firmas vinculadas à EdC "são empresas privadas, inseridas no mercado, que salvaguardam a propriedade particular dos bens, colocando o lucro em comunhão: uma visão humanista cristã do mundo dos negócios" (LEITÃO e SPINELLI, 2008, p. 453).

Deve-se destacar que a proposta da EdC não entra em conflito com o capitalismo no que se refere ao modo de produção - o lucro, a propriedade dos bens de produção nas mãos dos empresários, os mecanismos de acumulação e de produção da riqueza/pobreza não são questionados; ao contrário, como apontam Carvalho e Guareschi (2009), a EdC articula representações consolidadas e representações emergentes do capitalismo contemporâneo a representações religiosas. O que haveria de radical na EdC são seus aspectos culturais, ao propor um modelo econômico pautado em valores como a comunhão, a partilha voluntária dos bens, a reciprocidade e o amor (GUI e BRUNI, 2001).

Assim, enquanto as empresas discutem cenários e revisam suas estratégias, a fim de obter vantagem competitiva por meio do elemento humano, as empresas de Economia de Comunhão já trazem, em suas práticas de gestão de pessoas, o elemento humano como seu principal ativo. Tais práticas passam por um viés que interliga a gestão de pessoas e as relações de trabalho aos valores e formas de atuação organizacional propostos pela EdC, consolidados em sua Carta de Princípios.

A Carta de Princípios baseia-se nos valores essenciais que norteiam as relações de trabalho das empresas que se vinculam à economia de comunhão, bem como às empresas que desejam fazer parte dessa proposta, sendo, a partir de então, condição sine qua non para que uma empresa seja caracterizada como empresa de economia de comunhão (EEdC).

Entender a dinâmica de novas propostas econômicas e organizacionais, bem como a forma de alcançar seus objetivos através das relações de trabalho, pode revelar novas possibilidades para a gestão de pessoas na contemporaneidade. Os conceitos e as ferramentas usuais da gestão de pessoas foram desenvolvidos para atender às necessidades de empresas concebidas a partir dos valores culturais do capitalismo, diferentes da proposta da $\mathrm{EdC}$ - que, apesar de estar orientada para a obtenção do lucro, apoia-se sobre o princípio de que a pessoa é o foco central de atenção. À medida que, na dinâmica do capitalismo flexível, o elemento humano ganha importância determinante na produtividade do capital, explorar experiências que se estruturam, ao

\footnotetext{
${ }^{4}$ Termo utilizado para definir o produto das relações humanas nas empresas de economia de comunhão (EEdC) (gratuidade, unidade, amor recíproco).
} 
menos em tese, a partir desse elemento, apresenta-se como campo a ser explorado pela via da pesquisa na área de administração.

Assim, este estudo dedicou-se ao desafio de entender como funcionam as relações de trabalho nesse cenário, buscando, mais especificamente, responder à seguinte questão: “As empresas do Polo Spartaco coadunam o discurso exposto na Carta de Princípios da Economia de Comunhão com sua prática cotidiana na gestão de pessoas?".

A pesquisa teve como foco as empresas brasileiras, aderentes ao projeto da EdC, localizadas no espaço físico do Polo Spartaco, no município de Cotia, no estado de São Paulo. Realizada nas dependências do Polo Spartaco em outubro de 2011, ela levou em consideração as práticas de gestão de pessoas a partir dos valores internos que caracterizam as EEdCs por meio da Carta de Princípios, abordando a atração e seleção de pessoas, capacitação e desenvolvimento, os tipos de remuneração e programa de benefícios disponíveis aos colaboradores e a adesão aos valores organizacionais.

\section{Referencial Teórico}

\section{Economia de Comunhão}

Para entender a EdC, sua construção histórica e estrutura, é necessário conhecer sua gênese: o Movimento dos Focolares.

Em um cenário de destruição, no auge da Segunda Guerra Mundial, um grupo de amigas, todas jovens, liderado por Chiara Lubich, reunia-se em torno de uma fogueira no porão das ruínas de uma casa, em Trento, na Itália, em 1943. Em suas conversas, idealizavam um movimento que fosse capaz de unir as pessoas por meio da espiritualidade e da unidade entre as nações, a fim de que nunca mais o mundo passasse por um momento como aquele, e tiveram, assim, a revelação "sobre quem é verdadeiramente Deus: amor" (LUBICH, 2000, p. 10).

Chiara Lubich e suas amigas - entre elas Ginetta Calliari, que teve grande importância no desenvolvimento do movimento no Brasil - formavam um grupo que procurava viver segundo o modelo das primeiras comunidades cristãs, socorrendo as vítimas da guerra e compartilhando com os mais necessitados tudo o que tinham. Em poucos meses, formou-se uma comunidade com cerca de 500 pessoas. Nascia assim o Movimento dos Focolares. Nos anos seguintes, o movimento cresceu na Itália e, a partir de 1956, espalhouse pela Europa e outros continentes e alcançou cristãos de diversas referências teológicas, ultrapassando as barreiras do catolicismo. Hoje, o Movimento dos Focolares dialoga com diversas religiões e culturas, como o judaísmo, budismo, taoísmo etc., favorecendo, assim, a concretude de obras sociais em todo o mundo.

No Brasil, o Movimento dos Focolares se difundiu no final da década de 1950, alcançando pessoas de todas as camadas sociais, com e sem vínculo religioso (LUBICH, 2000). Atualmente, é um vasto movimento, abrangendo cerca de 7 milhões de membros em centenas de países (VANDELEENE, 2003).

Para Burckart (2002, p. 75) o Movimento dos Focolares baseia-se "em uma visão antropológica, caracterizada pela superação do subjetivismo (com todas as suas formas modernas, como o individualismo e o liberalismo), por meio de um estilo de vida comunitário". Para que se possa compreender esse estilo de vida em comunidade, proposto pelo Movimento dos Focolares, e sua importância, faz-se necessário conhecer a base dessas comunidades: as Mariápolis.

As Mariápolis são uma das mais típicas realizações do Movimento dos Focolares, sendo, hoje, mais de 70 espalhadas nos cinco continentes. Podem ser definidas como um esboço de sociedade nova com casas, 
escolas, oficinas de trabalho etc., cuja lei é o amor recíproco, proposto pelo Evangelho; no entanto, cada uma dessas cidadelas tem características próprias, de acordo com o ambiente onde estão inseridas.

No Brasil, a primeira cidadela foi instalada em Recife, em 1958, primeiro solo a receber as ideias do Movimento dos Focolares fora do continente europeu. Porém, foi em Vargem Grande Paulista, a $47 \mathrm{~km}$ de São Paulo que nasceu a Mariápolis, que viria a ser a sede nacional do Movimento dos Focolares no Brasil. Inicialmente, essa cidadela recebeu o nome de Araceli e, após alguns anos, em homenagem a Ginetta Calliari - cofundadora do Movimento dos Focolares -, seu nome foi alterado para Mariápolis Ginetta e conta, atualmente, com cerca de 300 habitantes.

Nessa localidade foi criado o primeiro polo empresarial do projeto Economia de Comunhão no Brasil, em 1994, denominado Polo Spartaco. Os polos empresariais desempenham papel fundamental na viabilização e visibilidade do projeto da EdC. De acordo com Bruni (2002, p. 14), nos polos produtivos deverão estar as empresas que vivem de forma intensa o projeto, as quais "deverão funcionar como um farol, um laboratório onde é destilado um novo estilo de atuação econômica". Existe outro polo no Brasil, localizado na cidade de Igarassú-PE, denominado Polo Ginetta.

\section{O projeto economia de comunhão}

De acordo com Calliari (2000), durante uma viagem de Chiara Lubich ao Brasil, ela percebeu, ao sobrevoar a cidade de São Paulo, o contraste entre luxuosos arranha-céus e a situação da população que vive em condições de extrema pobreza na periferia da cidade. Na busca de uma solução para amenizar essa realidade, Chiara Lubich convidou os empresários e a comunidade do movimento no Brasil a se empenhar em um ideal no qual pudessem contribuir de forma efetiva para a redução dessa disparidade, lançando, assim, em 29 de maio de 1991, o projeto da EdC: "Temos que impelir os empresários a produzirem sempre mais lucros, portanto, a melhorarem sempre como empreendedores, para ganhar mais e para que os lucros sejam distribuídos" (LUBICH, 2000, p. 13).

Chiara Lubich buscou ligar o movimento à academia por meio de um grupo de universitários, delegando a eles a missão de estudar e apropriar à sociedade acadêmica esse novo modelo de economia: "Eu agora vos digo uma ideia, mas depois a aplicação concreta, sob um aspecto ou outro, a vantagem que poderá trazer seja para a economia empresarial, seja para a economia de um país ou de uma nação, vocês é que têm que aprofundar e investigar" (LUBICH, 2002, p. 13).

Em 2010, a EdC alcançou grande difusão midiática em diferentes contextos em todo o mundo. O Movimento dos Focolares aponta dois principais pontos que suscitaram esse interesse pela EdC e deram início a apresentações e congressos:

i) a citação da economia "civil e de comunhão" feita pelo Papa Bento XVI na encíclica Caritas in Veritate;

ii) a necessidade de valores diferentes no âmbito da vida econômica, evidenciada pela crise econômica mundial em 2008.

De acordo com o Relatório EdC 2009/2010, o dia 7 de julho de 2010 pode ser definido como uma data histórica para a EdC, devido ao contexto da encíclica de Bento XVI Caritas in Veritate.

A encíclica traz uma importante inovação, com particular relevância para a teoria e a prática econômica contemporânea, em relação ao princípio de gratuidade: ser reconhecido como princípio fundante também para a economia e para o mercado. Isso significa que, segundo Bento XVI (2009), a gratuidade não é uma 
categoria para ser aplicada somente ao setor non-profit, ao voluntariado ou à economia social, mas a toda a vida econômica, dos bancos às empresas multinacionais.

A partir da publicação, emerge imediatamente um notável interesse midiático em torno da EdC como, talvez, uma tentativa de trazer à tona outros modos de economia que permitam menos vulnerabilidade a crises. Em particular nos Estados Unidos, blogs e jornais, como o Wall Street Journal e o National Catholic Reporter, trouxeram à tona a EdC e procuraram explicá-la aos leitores por meio de entrevistas com empresários ligados ao movimento.

A maior evolução na quantidade de empresas que aderiram ao projeto da EdC ocorreu até 2003, quando chegou a 797 empresas. A partir desse ano houve uma queda acentuada, chegando a 735 empresas em 2005. No entanto, após a crise econômica mundial de 2008, houve novo crescimento do número de empresas, atingindo-se em 2011 a marca histórica de 840 EEdCs, presentes em todos os continentes.

As empresas vinculadas à EdC visam ao lucro e sobrevivem a partir das receitas geradas com a venda de seus produtos e serviços. Cerca de metade são empresas de serviços, seguida pela indústria e uma fatia menor voltada ao comércio.

Os lucros das EEdCs aumentaram 7,6\%, chegando a um valor aproximado de $€ 770$ mil, no fechamento de 2010 (EDC, 2011).

As EEdCs apresentam um ponto fundamental que as diferenciam de outros empreendimentos: a partilha e a destinação dos lucros. A EdC se baseia em 3 pilares de igual importância, no que se refere à distribuição dos lucros das empresas. As empresas vinculadas à EdC buscam destinar o lucro a três finalidades. Após o pagamento dos impostos, a primeira parte deverá ser destinada ao incremento da própria empresa; a segunda, para auxiliar as pessoas necessitadas e que fazem parte do projeto de comunhão de bens; e a terceira, para o desenvolvimento de estruturas de comunhão, visando à formação de novos trabalhadores e novos empresários (LUBICH, 1996; QUARTANA, 1992).

As características, princípios e valores podem ser adotados por qualquer empresa, porém, para a adesão à EdC são convidadas empresas despertas para o princípio da solidariedade, os valores ético-espirituais nos negócios, a prática do bem comum, a priorização do trabalho sobre o capital, a destinação universal dos bens e a preocupação com a dignidade humana. A adesão deve ser isenta de toda pressão do mercado, de toda crise de consciência, de todo cálculo de custo/benefício. A adesão não pode "[...] ser imposta ou obrigada, quer por meios coercitivos, quer por meios subliminares, como os utilizados pelo marketing" (ARAÚJO, 1992, apud SERAFIM, 2001, p. 79).

\section{Valores da economia de comunhão}

Os valores da EdC oferecem uma identidade geral para as empresas vinculadas ao projeto, além de direcionar e manter o equilíbrio das organizações. Entre outros aspectos, eles expressam uma vida comunitária, que são características de sua espiritualidade, como se vê abaixo:

- Sobrevivência financeira: a partir do trabalho, que indica a necessidade de pessoas competentes que façam as empresas funcionar bem e que possam gerar lucros, para ser possível a comunhão.

- Resultados compartilhados: a estrutura da empresa (e não só as pessoas, isoladamente) deve irradiar a missão que escolheu, seja na forma de apoio financeiro, seja na troca de experiência entre as empresas, bem como no ato de irradiar uma nova realidade econômica para a sociedade, políticos etc. 
- Fidelidade à missão: eleva a empresa a uma nova realidade. Os dois aspectos anteriores criam a possibilidade de exercer a comunhão e irradiar sua missão, enquanto esse aspecto eleva a empresa a uma nova concepção.

- Compromisso com a cidadania: faz com que haja um grande respeito ao meio ambiente e à saúde física de todos, em síntese, respeito ao ser humano.

- Harmonia: trata de criar sistemas de gerência e estruturas organizadoras capazes de promover o trabalho em grupo e promover o crescimento individual. Aqui, também se consideram os locais de trabalho, a ordem, para que todos que tenham contato com a empresa se sintam bem.

- Desenvolvimento contínuo: esse valor refere-se à realização da comunhão, à irradiação da experiência, à elevação do conceito de empresa, ao cuidado com o meio ambiente e a saúde das pessoas, bem como à harmonia no ambiente de trabalho.

- Comunicação e intercâmbio de experiências: permitem um sistema gerencial que promova o alinhamento de todos em torno da missão da empresa e que crie unidade.

Um dos desafios da EdC é resgatar os valores comunitários nas organizações empresarias no contexto das modernas relações de trabalho, iniciativa que se apoia no proposto por Buber (1987) e por Drucker (2001), de que os seres humanos necessitam viver em comunidades, inclusive de trabalho, de forma a possibilitar sua realização pessoal e sua contribuição, para que possam sentir-se importantes na dinâmica empresarial.

\section{Carta de princípios das empresas da economia de comunhão}

Em 1999, foi realizado em Grottaferrata, Itália, o encontro do Bureau Internacional de Economia e Trabalho, do qual participaram empresários, estudantes e pesquisadores dedicados ao projeto de economia de comunhão. Nesse encontro foram definidos os princípios para a gestão de uma empresa da Economia de Comunhão, a partir de seus valores, alinhados à missão da EdC, podendo ser aplicados a qualquer empresa, desde que ela seja constituída por pessoas com disposição voluntária para a lógica da comunhão (BARAÚNA, 1999).

Essa Carta de Princípios contempla várias relações que ocorrem em qualquer atividade empresarial e aponta os comportamentos que devem ser seguidos para que a firma seja caracterizada como uma empresa de EEdC. Assim, são apresentados a seguir os tópicos contemplados na Carta de Princípios.

\section{A) Empresários, trabalhadores e empresa}

- Formular estratégias, objetivos e planos econômicos considerando os critérios típicos de uma gestão correta.

- Investir com prudência e particular atenção para a criação de novas atividades geradoras de empregos.

- Lembrar que no centro da empresa está a pessoa humana, e não o capital.

- Utilizar o talento dos funcionários do melhor modo possível, favorecendo a criatividade, a responsabilidade e a participação nas decisões.

- Adotar medidas para ajudar os funcionários que passam dificuldades.

- Administrar a empresa com a finalidade de produzir lucros. 


\section{B) Relacionamento com os clientes, com os fornecedores, com a sociedade civil e com terceiros}

- Esforçar-se para oferecer bens e serviços úteis, de qualidade e por preços justos.

- Trabalhar com profissionalismo, para construir e reforçar boas e sinceras relações com os clientes, os fornecedores e a comunidade.

- Estabelecer relacionamento leal com os concorrentes, apresentando a qualidade dos próprios produtos e privando-se de ressaltar os defeitos dos produtos e serviços dos outros.

\section{C) Ética}

- Promover, através do trabalho, o crescimento espiritual de todos os membros da empresa.

- Respeitar as leis e manter um comportamento eticamente correto perante as autoridades fiscais, os sindicatos e as organizações institucionais.

- Agir da mesma forma com os funcionários, dos quais a empresa espera semelhante comportamento.

- Esforçar-se não só para respeitar os próprios deveres contratuais, mas, também, para avaliar os reflexos objetivos da produção da empresa no bem-estar dos consumidores, no que se refere à qualidade de seus produtos e serviços.

\section{D) Qualidade de vida e de produção}

- Transformar a empresa em uma verdadeira comunidade, o que constitui um dos principais objetivos dos empresários de EdC.

- Reunir-se periodicamente com diretores e gerentes para avaliar a qualidade dos relacionamentos.

- Empenhar-se para resolver situações difíceis, com a consciência de que esse esforço pode ter efeitos positivos nos membros da empresa, estimulando inovações e incrementando a maturidade e produtividade.

- Considerar a saúde e bem-estar de cada funcionário.

- Propiciar adequadas condições de trabalho - respeito às normas de segurança, ventilação, iluminação apropriada e outras.

- Evitar carga horária excedente, de modo que ninguém fique sobrecarregado.

- Construir relacionamentos de amizade no ambiente de trabalho, onde deve reinar o respeito, a confiança e a estima recíproca.

- Produzir bens e serviços garantidos, tomar as devidas providências para não danificar o meio ambiente e procurar economizar energia e reservas naturais, não só durante a produção, mas todo o ciclo de vida do produto.

\section{E) Harmonia no local de trabalho}

- Adotar sistemas de gerência e estruturas organizacionais capazes de promover tanto o trabalho em grupo quanto o crescimento individual.

- Manter os locais de trabalho organizados, limpos e agradáveis, deixando o ambiente harmonioso. 


\section{F) Formação e instrução}

- Favorecer a criação de uma atmosfera de ajuda recíproca, de respeito e de confiança.

- Colocar à disposição, livremente, os talentos, ideias e capacidades de cada um, em benefício do crescimento profissional de todos.

- Estabelecer critérios de seleção do pessoal e de programação de desenvolvimento profissional para os funcionários.

- Promover frequentemente cursos de reciclagem e aprendizado.

\section{G) Comunicação}

- Estabelecer uma comunicação aberta e sincera, que favoreça o intercâmbio entre diretores e funcionários.

- Estender essa comunicação a todas as pessoas que contribuem para o desenvolvimento da EdC.

- Utilizar os meios mais modernos de comunicação, com a finalidade de desenvolver relacionamentos econômicos, úteis e produtivos.

- Alegrar-se com o sucesso e valorizar as dificuldades, as provações ou o insucesso dos outros, em um espírito de colaboração e solidariedade.

Esses princípios sustentam o que Pinto e Leitão (2006) destacam como sendo o diferencial das EEdCs: a forma como as pessoas tratam umas às outras, incluindo os clientes, os fornecedores e os demais stakeholders. Essa qualidade dos relacionamentos interpessoais e interorganizacionais representa um capital relacional que se soma às redes de contato comerciais que as EEdCs formam, constituindo "uma zona de amortecimento de choques para suportar pressões de mercado" (LEITÃO e SPINELLI, 2006, p. 453). Tendo em vista a amplitude do Movimento dos Focolares, essas redes podem, potencialmente, ganhar dimensões globais (LINARD, 2003).

\section{A gestão de pessoas no contexto contemporâneo}

Apesar das grandes transformações no século XX e XXI, em função de pressões que receberam, tanto do contexto externo quanto do contexto interno, como a globalização, a era da informação, do conhecimento e do capital intelectual, algumas empresas ainda seguem princípios de gestão de pessoas alinhados a uma visão do passado. No entanto, outras estão provocando mudanças nessa posição em relação às pessoas nas organizações, pois o trabalho é cada vez mais intelectual e menos braçal e as pessoas não são mais meros recursos alocáveis, mas parte estratégica e integrante da dinâmica organizacional. As pessoas estão se preocupando com a qualidade de vida no trabalho, suas relações interpessoais, o respeito do superior para com seus subordinados e a ética profissional. Tais fenômenos têm interferido até nas nomenclaturas utilizadas, que fazem referência às pessoas no contexto organizacional com o termo "colaborador", em detrimento do termo "empregado".

Nesse cenário, as organizações foram obrigadas a observar melhor o conjunto de expectativas e necessidades das pessoas no âmbito do trabalho. Essas pressões têm sua principal origem na forma como as pessoas passaram a enxergar sua relação com o trabalho e com a empresa a partir dos anos 1980 (DUTRA, 2001).

O crescimento das organizações, o aumento da complexidade das tarefas, a crescente necessidade de lucratividade, a globalização e o avanço da tecnologia, dentre outros fatores, compõem as novas demandas organizacionais no cenário competitivo atual (KAPLAN e NORTON, 1997; ULRICH, 2003). Apesar de nem 
todas as organizações ou mercados sofrerem da mesma forma as pressões dessas variáveis, de alguma forma, elas interferem no ambiente de negócio no qual as organizações estão inseridas e devem ser considerados na análise de impactos que geram na gestão das pessoas.

Ao participar do processo de elaboração e definição das estratégias corporativas, a gestão de pessoas atua como parceira estratégica do negócio, o que implica o desenvolvimento e acompanhamento das práticas de gestão do corpo funcional, alinhada às estratégias globais da empresa, tornando, assim, a gestão de pessoas um braço estratégico das organizações (ULRICH, 2003).

Alguns autores apontam tendências gerais no papel estratégico da gestão de pessoas nos moldes atuais. O primeiro deles é apoiado pela transformação na forma de trabalho, onde há o deslocamento do foco de atuação via controle dos trabalhadores para o foco via desenvolvimento humano; o segundo está diretamente ligado à necessidade de considerar as pessoas para alcançar os resultados, a partir do estímulo à participação nas questões estratégicas organizacionais; e, por último, a descentralização de poder, enfatizando a necessidade de uma comunicação autêntica, em todas as direções e sentidos, na organização (DUTRA, 2001; FISCHER, 2001; FLEURY e FLEURY, 2004).

Ulrich (2003) considera que a realidade competitiva contemporânea demanda novas formas de observar a gestão de pessoas e afirma que, nos últimos anos, o papel dos gestores de pessoas foi direcionado do qualitativo para o quantitativo; do policiamento para a parceria; do foco no curto prazo para o longo prazo; do administrativo para o consultivo; do foco interno para foco externo e concentrado no consumidor; das posturas reativas para preventivas; e do foco na atividade para o foco nas soluções. Porter (1989) também sustenta que a forma de gerenciar as pessoas no contexto organizacional afeta a vantagem competitiva em qualquer empresa, podendo ser, em alguma delas, a chave para a vantagem competitiva.

Essa é a denominada gestão estratégica de pessoas, definida por Marras (2000, p. 253) como: "A gestão que privilegia como objetivo fundamental, através de suas interações, a otimização dos resultados finais da empresa e da qualidade dos talentos que a compõem".

O que se percebe é que os papéis dos gestores de pessoas só fazem sentido à medida que estejam alinhados às diretrizes organizacionais em uma visão estratégica ampla, levando-se em consideração não apenas o setor responsável por gerir pessoas, mas capacitando todos os gestores para gerir pessoas (ULRICH, 2003). Assim, a gestão de pessoas não se seria mais prisioneira, na concepção de Fischer (2001), de um sistema, área ou setor específico, monopolizando instrumentos e práticas instituídas para o direcionamento do comportamento humano no ambiente de trabalho, mas, sim, um amplo conceito direcionado ao corpo funcional dentro da gestão estratégica orientada ao negócio.

Nesse direcionamento, "as empresas passaram [...] a depender cada vez mais do grau de envolvimento e comprometimento das pessoas com seus objetivos estratégicos e negócios" (DUTRA, 2002, p. 25). O grande desafio é conquistar e manter as pessoas na organização, trabalhando e dando o máximo de sua contribuição aos fins produtivos.

Nesse esforço, as organizações percebem a importância do trabalho integrado entre a área de gestão de pessoas e as demais áreas da empresa, bem como a necessidade de enriquecimento das atividades interligando os processos de atração, seleção e treinamento e desenvolvimento com a área de remuneração, áreas vitais na formulação e implementação das estratégias organizacionais. Assim, atrair, selecionar, capacitar, desenvolver e remunerar são partes de uma engrenagem que não funciona em sua plenitude se não estiver alinhada aos valores organizacionais da empresa. No entanto, no contexto organizacional contemporâneo, os valores não precisam apenas estar em coerência com a prática, mas agregar valor aos indivíduos, à sociedade e à empresa (VIEIRA e CARDOSO, 2003). 
A construção e consolidação dos valores organizacionais constituem tarefa primordial da área de gestão de pessoas. Não obstante, cabe, especialmente, às lideranças da empresa criar condições para que essas mudanças sejam integradas de modo funcional à dinâmica empresarial (DAVEL e VERGARA, 2001).

Alguns autores afirmam que os valores organizacionais podem ser estudados a partir da percepção dos funcionários e têm a função de atender tanto os objetivos organizacionais quanto as necessidades dos indivíduos (TAMAYO, 1996; TAMAYO e BORGES, 2001; TAMAYO e GONDIM, 1996).

Assim sendo, a gestão de pessoas atua como agente estratégico dessas mudanças na consolidação dos valores, ao auxiliar as organizações, capacitando-as a garantir que tais valores sejam definidos, desenvolvidos e instituídos de maneira oportuna, além de atuar como mediadora na discussão e adaptação dos valores às condições do negócio (ULRICH, 2003).

\section{A gestão de pessoas diante dos valores das empresas de economia de comunhão}

As EEdCs devem seguir, em sua gestão, valores organizacionais específicos de vida empresarial comunitária, que tem por finalidade a promoção do ser humano e a vida em comunidade.

De acordo com Calliari (2000, p. 20), "a proposta de Chiara Lubich era montar empresas com pessoas éticas e competentes, dispostas a partilhar, com os mais necessitados, os resultados de seu trabalho", bem como, "atrair pessoas com essas características, de empresas já existentes, insatisfeitas com o atual nível ético das práticas empresariais e com a crise socioambiental que castiga o planeta". Dessa forma, atualmente o projeto tem esses dois perfis de empresário.

Esses valores apontados por Chiara Lubich foram desdobrados na Carta de Princípios, que contempla os comportamentos que devem ser seguidos para que ela possa ser vinculada à EdC. Essa carta, entretanto, teoriza o relacionamento e compromisso com a sociedade civil, a ética e relações com fornecedores e clientes, mas, especialmente, a enculturação dos valores internos da EdC nas relações de trabalho. Tais valores organizacionais levam em conta, primordialmente, a prática das relações humanas, sendo o centro de sua dinâmica o ser humano.

Uma vez que "todo fazer humano implica uma 'interpretação' das coisas que manipula como todo teorizar é extensão do fazer ao nível da representação, não é, pois, legítimo extremar a distinção entre teoria e prática" (GUERREIRO RAMOS, 1958, p. 79), assim, as empresas de EdC e seus funcionários devem agir de acordo com os valores organizacionais esposados em sua Carta de Princípios (BRUNI, 2002).

A vinculação de determinada empresa à EdC não deve ser obrigatória ou implementada por meios coercitivos, assim como a adesão aos valores da EdC, no entanto, para que uma empresa seja caracterizada como EEdC, ela deve seguir rigorosamente tais valores (SERAFIM, 2001).

A adesão aos valores, entretanto, está intrinsecamente ligada à maneira pela qual a empresa comunica, difunde e, principalmente, como ela administra tais valores, uma vez que os valores são visíveis no ambiente organizacional, a partir de atos e pensamentos automáticos, inseridos em fluxos de comunicação-informação, decisão-autoridade e na maneira como as pessoas são tratadas na organização (ULRICH, 2003).

Aparentemente, é o que propõem as empresas vinculadas à EdC. Seus valores organizacionais, primordialmente tratados como requisito para ser caracterizados como parte desse grupo, partem em direção a objetivos comuns, independente do segmento no qual as empresas estão inseridas, e, independentemente de qual percentual é destinado ao objetivo final, a partilha. Essa poderia ser uma resposta às pressões das mudanças no macroambiente organizacional e à própria cultura capitalista, que podem revelar algum 
diferencial no escopo das empresas da EdC: do saber como fazer (lucro) para o saber por que fazer (EDC, 2011).

Uma vez que os colaboradores são parte estratégica e integrante da dinâmica interna das organizações, as empresas têm buscado pessoas motivadas para compor seu quadro funcional, pessoas com valores similares aos esperados pela organização, o que faz com que a área de gestão de pessoas tenha de estar integralmente alinhada, não somente aos valores organizacionais, mas, sobretudo, às estratégias da organização, a fim de promover um processo de seleção eficaz e de manter a integralidade de todo o sistema de gestão de pessoas. Entretanto, são os valores, por meio das pessoas, os responsáveis pela forma de ser das empresas, pois os valores representam convicções básicas que definem que um modo de conduta é preferível a outro (ROBBINS, 1999).

Por serem os valores a expressão da cultura organizacional, Morgan (1996) a define como um sistema vivo e ativo de relações, através do qual os indivíduos criam e recriam os contextos nos quais vivem. É por meio da interação entre os valores dos indivíduos e os da organização que se estabelece o contrato psicológico que alinha e integra objetivos individuais e coletivos, estabelecidos, essencialmente, nos processos de identificação dos indivíduos com aspectos da cultura organizacional. A gestão de pessoas se apropria desse conhecimento e, por meio de suas políticas, estabelece mecanismos e práticas de uma gestão alinhada às estratégias dos negócios.

No entanto, também são esperadas da área de gestão de pessoas reflexões críticas que permitam o reconhecimento da dependência da condição de trabalho do indivíduo na organização à conformidade dos seus valores pessoais aos valores que compõem o código moral associado ao trabalho (NARDI, 2004). Espera-se, ainda, uma atuação ativa da área em prol do desenvolvimento humano - em que pese a dificuldade de equilibrar esse aspecto e as demandas produtivas.

A gestão de pessoas é uma área composta por diversas subáreas, responsáveis por deslocar para o gestor direto as atribuições de um líder, um gestor de pessoas. É nesse ponto que se percebe, também, a presença da liderança carismática de Lubich na consolidação de suas diretrizes para a formação de uma cultura de comunhão, baseada na solidariedade e na partilha dos lucros nas empresas vinculadas à EdC (LUBICH, 2000).

A partilha dos lucros, pilar da EdC, remete à distribuição de lucros e resultados, adotados pelas empresas em outros tipos de economia, bem como a forma de remunerar seus profissionais. Tendo visto que o lucro se destina, em parte, para pessoas necessitadas, em parte, para investimento na formação de "homens novos" (LUBICH, 2000), resta saber qual parte do lucro é destinada ao reinvestimento na própria empresa, é investida no capital humano em termos de desenvolvimento e/ou é distribuída em remuneração para os funcionários, uma vez que, de acordo com Bruni (2002), o ser humano é o centro da atividade econômica nas empresas da EdC.

Dentre outros pontos pertinentes à área de gestão de pessoas no contexto da Carta de Princípios estabelecidas para as empresas de EdC encontram-se: a comunicação, a ética e qualidade nos relacionamentos e o compromisso com a sociedade, os fornecedores e os clientes. Porém, a partir da consolidação de um valor específico, a gestão de pessoas nas empresas vinculadas à EdC pode alcançar todos os outros: fidelidade à missão e aos valores.

Assim sendo, a Carta de Princípios é um elemento norteador para que a gestão de pessoas possa fazer um trabalho eficaz de consolidação dos valores adotados pelas empresas vinculadas à EdC. No entanto, a adesão aos valores organizacionais passa pelas práticas de gestão de pessoas, mas, sobretudo, pela gestão das lideranças e pela forma com que os funcionários percebem tais valores. 
Cabe, por fim, questionar se a gestão de pessoas nas EEdCs não representa uma estratégia "suavizada" pelos valores que articula - de constituição de sujeitos adequados aos interesses produtivos, pois, como apontam Carvalho e Guareschi (2009, p. 98):

O perfil do trabalhador da EdC, embora os empresários e teóricos afirmem seguir uma outra racionalidade, serem guiados por seus princípios religiosos, é o mesmo do "profissional ideal" requisitado pela produção flexível: leal, dedicado, produtivo e criativo. Assim, através do relacionamento próximo e amistoso estabelecido com os trabalhadores, os empresários da EdC alcançam o que as empresas tradicionais buscam incessantemente através de políticas sofisticadas de gestão de pessoas.

\section{Aspectos Metodológicos}

O estudo teve caráter descritivo, tendo em vista que descrever favorece a abrangência dos "aspectos gerais e amplos de um contexto social", e, além disso, "[...] permite ao pesquisador a obtenção de uma melhor compreensão do comportamento de diversos fatores e elementos que influenciam determinado fenômeno" (OLIVEIRA, 1997, p. 117).

Quanto à abordagem, esta se caracterizou como qualiquantitativa. No entanto, a abordagem quantitativa foi utilizada como informação complementar, a fim de agregar mais informações à pesquisa, trazendo a impressão dos funcionários sobre a gestão de pessoas nas EEdCs.

No que se refere à abordagem qualitativa, esta se propôs a analisar com profundidade as informações obtidas na gestão de pessoas das EEdCs, avaliando suas características específicas e subjetivas, uma vez que, em se tratando de pessoas e valores, é fundamental "captar o significado particular que o próprio protagonista atribui a cada fato e de contemplar esses elementos como peças de um conjunto sistemático", a fim de [...] "captar a essência deste processo para interpretar", bem como "[...] captar o sentido dos diferentes conteúdos" (OLABUÉNAGA, 1999, p. 15).

O estudo de caso qualitativo foi escolhido como estratégia metodológica, uma vez que esse método é adequado nos casos em que a pesquisa pretende relacionar vários aspectos de um mesmo fenômeno (YIN, 2005), além de permitir estudar vários ângulos de um mesmo objeto, investigando, em profundidade, suas relações por meio de uma abordagem holística.

O objeto desta pesquisa é o Polo Empresarial Spartaco, situado no município de Cotia-SP, a $4 \mathrm{~km}$ da Mariápolis Ginetta. O polo foi fundado em 1994, exatamente três anos após o lançamento do projeto de EdC. Seu nome é uma homenagem a Spartaco Lucarini, antigo companheiro de Chiara na fundação do Movimento dos Focolares.

O objetivo de sua idealização e construção foi dar viabilidade e visibilidade ao projeto EdC, proporcionando às empresas um local apropriado para se instalar e colocar em ação, como em um laboratório, essa nova experiência econômica.

O polo deve "efetivar o crescimento na direção dos bens relacionais. Esse é o diferencial do polo em relação a outros condomínios industriais: os bens relacionais, o equilíbrio que o suporte espiritual confere às relações também em nível empresarial" (LEIBHOLZ, 2003, p. 14).

O Polo Spartaco foi projetado para abrigar 10 empresas, além do escritório da empresa administradora do polo, da área comercial e de serviços. O terreno do polo tem $50.849,36 \mathrm{~m}^{2}$, sendo que na área de $37.446,66$ $\mathrm{m}^{2}$ estão instaladas 6 empresas em operação, restando espaço para 4 novas empresas. Os outros $13.402,70 \mathrm{~m}^{2}$ destinam-se a futuras instalações do centro comercial. 
As empresas em funcionamento no Polo Spartaco empregam cerca de 100 funcionários diretos e 50 indiretos nas empresas: Espri S. A. (administração do Polo Spartaco), Ecoar (produtos de limpeza), KNE-Rotogine (rotomoldagem de plásticos), Uniben (fomento mercantil), Prodiet Nutrição Clínica (distribuidora de medicamentos), AVN Embalagens (embalagens plásticas), além da Associação dos Funcionários do Polo Spartaco.

No momento da pesquisa, o polo contava com 99 funcionários diretos e 50 funcionários indiretos das empresas: Espri S. A. (administração do Polo Spartaco), Ecoar (produtos de limpeza), KNE-Rotogine (rotomoldagem de plásticos), Uniben (fomento mercantil), Prodiet Nutrição Clínica (distribuidora de medicamentos), AVN Embalagens (embalagens plásticas), além da Associação dos Funcionários do Polo Spartaco.

Na seleção dos sujeitos para responder às entrevistas semiestruturadas foi utilizada a amostra proposital, sendo escolhidos os gestores responsáveis pelas políticas de gestão de pessoas nas empresas, apontados por elas próprias.

Foram entrevistadas 4 gestoras, representando o total de 5 empresas do Polo Spartaco, como apresentado no Quadro 1.

Quadro 1

Entrevistados

\begin{tabular}{|c|c|c|}
\hline Participante & Empresa & Cargo \\
\hline P1 & Espri Empreendimentos, Serviços e Projetos Industriais & Gerente \\
\hline P2 & Uniben Fomento Mercantil & Diretora \\
\hline P3 & AVN Embalagens & Proprietária \\
\hline P3 & Ecoar Produtos de Limpeza Ltda. & Proprietária \\
\hline P4 & Associação dos Funcionários do Polo Spartaco & Presidente \\
\hline
\end{tabular}

Fonte: Elaborado pelos autores.

As empresas AVN Embalagens e Ecoar Produtos de Limpeza Ltda. foram representadas pela mesma entrevistada, proprietária de ambas.

$\mathrm{Na}$ fase quantitativa, foi aplicado um questionário. Assim, foram escolhidos funcionários aleatoriamente, em sua maioria dos setores administrativo e operacional, na medida da disponibilidade de cada um para responder o questionário. No entanto, até o final da pesquisa em campo retornaram 27 questionários.

Este estudo utilizou-se de 1) entrevistas semiestruturadas; 2) questionário; 3) observação direta; e 4) evidências documentais.

As evidências coletadas em campo foram obtidas por meio de entrevista semiestruturada em tópicos, preparada previamente à visita a campo, a fim de obter maior flexibilidade na formulação das perguntas e aplicadas aos gestores das empresas. Para Yin (2005), as entrevistas representam uma fonte essencial de evidências para estudos de caso, uma vez que a maioria delas trata de questões humanas. 
Paralelamente, foi aplicado questionário aos funcionários, a fim de obter a impressão deles em relação aos processos de gestão de pessoas, ocorridos na empresa em que trabalhavam, a partir dos valores expressos na Carta de Princípios.

Tais instrumentos foram manuseados pela pesquisadora de duas formas: as entrevistas foram aplicadas pessoalmente, em datas previamente agendadas com as empresas envolvidas na pesquisa, enquanto $o$ questionário foi aplicado de forma pessoal, em campo.

Outra fonte de coleta de evidência se deu por meio da observação direta. As evidências observacionais são, em geral, úteis para fornecer informações adicionais, bem como as evidências documentais, também utilizadas nesta pesquisa, por meio de documentos disponibilizados pelo Movimento dos Focolares e o Centro de Estudos Filadélfia.

No tratamento das evidências, as informações obtidas foram analisadas em busca de elementos relevantes para o estudo. As evidências obtidas por meio das questões fechadas do questionário mereceram tratamento estatístico e foram empregadas nos resultados finais, a fim de complementar ou confrontar a realidade relatada pelos gestores. Por outro lado, as evidências coletadas por meio das entrevistas foram submetidas à análise de conteúdo, servindo para clarificar a subjetividade expressa nas respostas, tal como propuseram Delgado e Gutierrez (1995).

Apesar do estudo de caso ser considerado como uma forma distintiva de investigação empírica, muitos pesquisadores ainda encaram o método com certas restrições, assim, as evidências observacionais e documentais desempenharam importante papel na complementação dos dados obtidos por meio de entrevistas e questionários, minimizando as limitações intrínsecas do método.

\section{Apresentação e Análise dos Resultados}

Do total de 6 empresas atuantes no polo no momento da pesquisa, 4 empresas e a Associação dos Funcionários participaram da pesquisa, sendo entrevistados 4 gestores, sendo que 1 deles respondeu por 2 empresas.

A empresa AVN contava com 38 funcionários, enquanto a Ecoar tinha 30 funcionários. Já a empresa Uniben possuía 4 funcionários, bem como a Espri S. A., responsável pela administração do polo e relacionamento com os acionistas. A Associação dos Funcionários contava com 1 funcionário direto.

Assim, as empresas pesquisadas no Polo Spartaco representavam no momento da pesquisa 77 funcionários do total de 99 funcionários diretos lá atuantes.

Apesar de estar no polo e fazer parte da EdC, cada empresa tem características próprias, bem como modelo independente de gestão. No entanto, segundo a gerente da Espri, o polo funciona "como um condomínio [...] quando tem uma situação, todo mundo conversa para resolver, aqui não é diferente".

A forma de agir em condomínio é bastante perceptível no que se refere à gestão de pessoas; uma vez que o polo abarca empresas de micro e pequeno porte em diferentes segmentos, descritas a seguir, torna inviável custear um setor específico de gestão de pessoas em cada empresa, o que faz com que suas práticas de gestão de pessoas, em grande parte administradas pelos proprietários das empresas ou por seus gerentes administrativos, sejam delegadas e centralizadas na Associação dos Funcionários, tornando-a um forte elo de interlocução entre as empresas e os funcionários.

A seguir são mostrados os resultados da pesquisa de campo, realizada sob a forma de entrevistas semiestruturadas, além da utilização de questionário e observação em campo. 
É necessário informar que outras duas empresas, responsáveis por 22 funcionários do total de 99 funcionários no Polo Spartaco, não participaram das entrevistas pelo fato de seus representantes estarem ocupados ou não estarem no Polo Spartaco na semana em que ocorreu a pesquisa de campo.

No entanto, não é objetivo desta pesquisa tratar os dados obtidos de forma individual, por empresa, mas analisar de forma geral as práticas de gestão de pessoas no Polo Spartaco, sob a perspectiva dos valores expostos na Carta de Princípios que rege as EEdCs.

\section{A gestão de pessoas no Polo Spartaco}

As práticas de gestão de pessoas pelas empresas do Polo Spartaco, estão centralizadas em grande parte nas atividades administrativas voltadas a questões legais, como controle de ponto, processos de admissão e demissão, confecção da folha de pagamento e efetivo pagamento de salário mensal aos funcionários.

No que se refere à gestão estratégica de pessoas, como remuneração, pesquisas de salários formais no mercado, realização de orçamento anual para atividades de gestão de pessoas, seja para contratação, retenção ou remuneração, não há processos estruturados: eles são tratados à medida que surgem as demandas.

A atração de pessoas acontece por meios diversos como o anúncio interno nos quadros de aviso, por meio de comunicação, para que alcancem a comunidade em torno do polo.

Os currículos habitualmente entregues na Associação dos Funcionários por estes e na empresa Espri S. A. por pessoas que vivem ao redor do polo e nas cidades vizinhas são encaminhados para as empresas, a fim de auxiliá-las nos processos de seleção, realizados internamente pela própria empresa.

Os processos de capacitação e desenvolvimento são tratados à medida que os gestores percebem demanda específica de aprendizagem ou quando os funcionários demonstram interesse em algum treinamento/curso. A associação também executa papel importante nos processos de capacitação e desenvolvimento, apurando necessidades e o desejo de desenvolvimento dos funcionários.

A qualidade de vida e a harmonia no ambiente de trabalho são levadas em consideração tanto pelas empresas quanto pela associação. No dia a dia, a associação é responsável por estar mais próxima dos funcionários, captando suas demandas e transformando-as em projetos junto às empresas do polo.

De acordo com a Carta de Princípios das EEdCs, a pessoa é o centro da empresa, e não o capital. No entanto, enquanto as ações de gestão de pessoas, nas empresas que não compartilham da EdC, normalmente são realizadas por um setor determinado, atualmente considerado estratégico, as empresas do Polo Spartaco utilizam a Associação dos Funcionários, entidade que promove e mantém ações de integração, qualidade de vida, aspectos sociais e financeiros dos funcionários.

Devido à importância da associação nos processos de gestão de pessoas e antes da análise da gestão de pessoas, a partir da Carta de Princípios das EEdCs, faz-se necessário expor, no próximo tópico, a forma de atuação e as práticas da associação descritas pela sua gestora.

\section{O papel da associação dos funcionários nos processos de gestão de pessoas do Polo Spartaco}

Inicialmente, não se cogitava a inserção da Associação dos Funcionários na pesquisa. No entanto, no decorrer das entrevistas, percebeu-se a necessidade de inseri-la, devido ao seu destaque nas iniciativas de gestão de pessoas no Polo Spartaco. 
Assim, a fim de detalhar as iniciativas da Associação dos Funcionários, as falas apresentadas neste tópico foram retiradas da entrevista com a participante 4(P4), representante da Associação.

A Associação busca intermediar diariamente as relações de trabalho entre as empresas e seus funcionários por meio de contato direto com o funcionário e as empresas.

Um dos benefícios oferecidos pelas empresas, em geral, trata-se do empréstimo consignado, no qual o funcionário solicita ao banco contratado pela empresa um empréstimo, que é descontado mensalmente em folha de pagamento, conforme contrato interno. Percebe-se que, no caso do microcrédito, além das diferenças de taxas e juros, cada caso é estudado, a fim de apurar a real necessidade do empréstimo, sendo, em alguns casos, resolvida de outra forma.

Além do microcrédito, a associação tem buscado oferecer novos benefícios a seus associados. No caso do plano odontológico, o fato de a Associação agrupar um número maior de beneficiários facilitou a negociação para que o preço fosse acessível aos associados. Como a associação não tem capital suficiente para responder pelo pagamento do plano odontológico, a responsabilidade do custeio do plano é dos próprios beneficiários.

O espaço da lan house tinha 4 computadores equipados com caixa de som e fone. É disponibilizado acesso à internet, que os funcionários utilizam gratuitamente durante o horário de almoço. No mesmo espaço há uma televisão 40 polegadas, que também fica ligada no horário do almoço. Ainda no mesmo espaço, há uma mesa de aproximadamente 15 lugares, outra mesa de apoio e dois micro-ondas. Um balcão separa essa área da cozinha, que contava com uma geladeira, um fogão, uma mesa com seis lugares e uma pia com balcão.

O almoço dos aniversariantes foi realizado, coincidentemente, em um dos dias da pesquisa, quando se pôde observar e conversar com alguns participantes.

Apesar de o convite se estender aos gestores das empresas, "a gente convida também, é um momento de integração", eles não participaram desse almoço, não puderam comparecer. Em conversa informal com um funcionário presente no almoço, este informou que acha que eles não vêm em todos os almoços, mas que as pessoas se sentem à vontade quando eles vêm, porque "são pessoas muito boas, muito simples".

Outro participante disse: "É muito bom esse almoço, a comida é muito boa, tem sobremesa e o pessoal aqui é muito bacana, foi bom a empresa ter feito isso pra gente".

Percebe-se nessa fala que, apesar de o almoço dos aniversariantes acontecer por iniciativa da associação, o funcionário a enxerga como sendo da própria empresa na qual trabalha, o que leva ao entendimento de que a associação e a empresa são, na perspectiva do funcionário, a mesma instituição, ou de que a associação é um setor da empresa.

Anualmente, é realizada a assembleia, que determina, por meio de votação, quem será o responsável pela gestão da associação. Nessa assembleia também é apresentado o balanço financeiro da associação, bem como os projetos concluídos e a concluir e as sugestões para o próximo ano. Nessa reunião também são levantadas as necessidades e os anseios dos associados.

Percebe-se, mais uma vez, o papel da associação no que se refere aos itens D e E da Carta de Princípios: a qualidade de vida e a harmonia no local de trabalho.

Uma vez que a associação ainda está em fase de estruturação, ao questionar quais seriam seus próximos passos e quais seriam seus projetos para o futuro foi obtida a seguinte resposta: "O grande desejo nosso é montar uma cozinha aqui no polo". 
O polo está situado em um local onde há pouco acesso a restaurantes, lanchonetes e ao centro da cidade. Um dos locais mais próximos que serve almoço fica em Vargem Grande Paulista e é acessível por meio de rodovia, no entanto, há empresas que entregam refeição no polo.

Ainda sobre novas iniciativas, obteve-se:

O que estamos fazendo também, durante o ano, daqui para frente, trabalhar os cursos, cursos de artesanato, cursos de motivação, cursos de educação, [...] Chamar o Sebrae para dar alguns cursos, empreendedorismo também. (P4)

A fala acima vai ao encontro de algumas ações previstas na Carta de Princípios, especialmente no eixo que trata da formação e instrução, que prevê a disponibilização de cursos de reciclagem e aprendizado.

Outra ação expressa na Carta de Princípios prevê a criação de uma atmosfera de ajuda recíproca, de respeito e confiança, prática observada quando questionado de que forma a associação poderia ajudar os funcionários em seus projetos particulares:

No Dia dos Pais foi oferecida uma caixinha de chocolate que nós compramos dessa associada, a mesma coisa fizemos no Dia da Secretária, para motivar essa associada que vende o chocolate. (P4)

As datas comemorativas e as festas que buscam a integração dos funcionários são oferecidas pela associação com a participação das empresas. Há uma preocupação em oferecer aquilo que é útil, como os brindes que são sorteados por meio de bingos e rifas.

As festas têm caráter familiar, geralmente são realizadas aos sábados e ocorrem no próprio polo. A participação não é obrigatória, no entanto, funcionários e empresários comparecem.

De acordo com a Carta de Princípios das EEdCs, a pessoa humana está no centro da empresa, prática que pode ser observada nas falas a seguir:

Tivemos agora pouco oito desligamentos e, aí, conseguimos recolocar todos eles, dois foram para uma empresa também de economia de comunhão em Recife e os outros a gente conseguiu recolocar aqui na região mesmo. (P4)

Por fim, completou:

Todo mundo é bem escutado aqui, às vezes a gente não tem a prática formal, escrita ainda, mas a gente sempre tenta buscar uma solução. (P4)

\section{A gestão de pessoas sob os princípios da economia de comunhão}

Segundo a Carta de Princípios da EdC, sete eixos constituem e regulamentam as relações profissionais e comerciais das empresas vinculadas ao projeto. Nesta pesquisa, foram levados em consideração apenas os eixos e suas vertentes que perpassam as relações de trabalho na gestão de pessoas.

A seguir, serão apresentadas as informações obtidas na pesquisa, a partir da sequência apresentada na Carta de Princípios, assim exposta: empresários, trabalhadores e empresa; ética; qualidade de vida e de produção e harmonia no local de trabalho (tratados em conjunto, aqui); formação e instrução; comunicação. 


\section{Empresários, trabalhadores e empresa}

Um dos pilares das EEdCs presente nesse eixo diz: "Lembrar que no centro da empresa está a pessoa humana, e não o capital". Questionadas sobre como se fundamenta isso na prática, obteve-se o seguinte depoimento:

O conceito é o mesmo, só que esse algo a mais que é você olhar o outro, a pessoa como esse diferencial, quer dizer, quem é o centro? É o homem. Então, acho que isso muda tudo, transforma tudo, que é o homem que realiza tudo, então, ele tem de ter dignidade. (P3)

$\mathrm{Na}$ fala acima, percebe-se que, apesar de a empresa fazer parte de um projeto que nasceu com objetivos de partilha e assistencialismo, a gestão da empresa se baseia em conceitos utilizados normalmente pelas empresas, onde o foco está na lucratividade e na competitividade. No entanto, apesar de ser voltados para o lucro, não excluem o ser humano e suas relações, mas o coloca como o centro da sua atividade econômica.

Duas vertentes complementares nesse eixo se referem à adoção de "medidas para ajudar os funcionários que passam dificuldades" e que a empresa utilize "o talento dos funcionários do melhor modo possível, favorecendo a criatividade, a responsabilidade e a participação nas decisões".

As gestoras entrevistadas deixam claro o orgulho e motivação em trabalhar em conjunto com os funcionários, ajudando na transformação e construção de "homens novos".

O último tópico desse eixo envolve a questão da administração da empresa com a finalidade do lucro. A distribuição do lucro, no que se refere à EdC, é conhecida por todos que fazem parte da empresa. Nos quadros de aviso estão afixadas as informações da participação das EEdCs nos projetos em todo o mundo. As informações também são disponibilizadas por meio de relatório anual e divulgadas nos congressos e seminários da EdC.

\section{Ética}

O primeiro ponto desse eixo trata do crescimento espiritual dos membros da empresa através do trabalho. Levando-se em consideração a natureza da EdC e sua relação com o cristianismo; a religião se mostrou uma questão importante a pesquisar, a fim de que se possa observar se há predominância ou preferência no momento da contratação por pessoas de uma mesma denominação religiosa, ou por ser membros do Movimento dos Focolares.

Todas as empresas pesquisadas enfatizaram que não há distinção de religião em nenhuma situação cotidiana nas relações de trabalho, como também não é um ponto considerado no momento de contratar um profissional para integrar seu corpo de funcionários, o que corrobora outro ponto desse eixo, que considera que a forma de agir da empresa com o funcionário deve ser semelhante à forma de agir do funcionário com a empresa.

Percebeu-se que o próprio Movimento dos Focolares não faz a distinção de religião, apesar de ter sua origem no cristianismo católico.

Outra vertente desse eixo trata dos compromissos com as leis que regem as relações de trabalho e o comportamento ético perante suas instituições reguladoras.

Para avaliar essa vertente foi pesquisada a posição das empresas no que se refere ao pagamento de salários de seus funcionários, à participação nos lucros, à bonificação, ao pagamento de benefícios legais e sociais. 
No entanto, o resultado apontou que não há uma política ou planejamento formal nas empresas, como também não há plano de cargos e salários.

A empresa, como organismo social, deve proporcionar o atendimento às necessidades básicas de seus empregados, assegurando a satisfação de tais necessidades seja por meio de benefícios, seja por meio de outros tipos de remuneração.

Os benefícios e vantagens concedidas, a título de pagamento adicional dos salários, compõem a remuneração total do trabalhador e são considerados remuneração indireta, devido ao seu caráter econômico-social.

No que se refere a benefícios, fica evidente, em todos os relatos, que a responsabilidade é direcionada à Associação dos Funcionários, apesar de algumas empresas oferecerem alguns benefícios.

Percebeu-se que parte dos benefícios oferecidos é proveniente do pagamento de parte da mensalidade da associação, efetuado pelos próprios funcionários, como é o caso do microcrédito. Parte do valor arrecadado é revertida em empréstimo.

O programa de microcrédito é bastante utilizado pelos funcionários, entretanto, é feito um estudo aprofundado de cada caso para que ele seja liberado.

\section{Qualidade de vida e de produção e harmonia no local de trabalho}

Esses dois eixos podem ser analisados em conjunto pela sua intrínseca ligação com as práticas observadas e pelas vertentes que os compõem na Carta de Princípios.

Percebeu-se, por meio de observação, o esforço no Polo Spartaco para que a qualidade de vida e de produção seja produto da harmonia no local de trabalho. "Transformar a empresa numa verdadeira comunidade" é um dos "principais objetivos dos empresários de EdC", é a vertente mais perceptível no polo, ainda mais evidente ao conhecer o papel da associação na harmonização das relações, na integração e na qualidade de vida dos funcionários do Polo Spartaco. Evidenciou-se, também, o direcionamento dessas práticas e iniciativas para a associação por parte das empresas.

É perceptível o clima de acolhida e tranquilidade no Polo Spartaco. Durante o horário de almoço, os funcionários se recolhiam nas calçadas e embaixo das árvores. O sorriso era uma característica marcante tanto das gestoras entrevistadas como dos funcionários da produção.

Os funcionários e a própria gestão acreditam que a forma com que se relacionam é um dos principais pontos de convergência da EdC. Apesar de estar em um ambiente profissional, as questões particulares de cada funcionário estão sempre em discussão com o objetivo de ajuda mútua.

Outro ponto importante é a finalidade do lucro produzido. Enquanto algumas empresas adotam instituições para que seus funcionários possam desenvolver trabalho voluntário, os funcionários se sentem motivados ao acreditar que, por meio do seu próprio trabalho, gerando lucro para as EEdCs, estão contribuindo com ações de melhoria para a comunidade em seu entorno e para a minimização da pobreza no mundo.

\section{Formação e instrução}

A empresa que deseja contar com profissionais eficientes necessita capacitá-los por meio de cursos e treinamentos, favorecendo novas descobertas e facilitando o desenvolvimento de habilidades e competências e a educação contínua. 
De forma geral, as vertentes desse eixo - o favorecimento de uma atmosfera de respeito e confiança, a livre disposição de ideias e talentos em benefício do crescimento profissional de todos, a programação de desenvolvimento profissional para os funcionários e a promoção frequente de cursos de reciclagem e aprendizado - podem ser observados pelas falas expostas neste tópico, apesar de as empresas pesquisadas não possuírem nenhuma política formal de capacitação e desenvolvimento, uma vez que é a partir da demanda apresentada que cada necessidade é trabalhada.

Quando se percebe que há necessidade de capacitação para o desenvolvimento do trabalho, estuda-se se é uma necessidade individual ou coletiva. Sendo individual, paga-se o curso para o funcionário; quando é coletiva, contrata-se uma empresa de treinamento para que os treinamentos sejam realizados no próprio polo.

Percebe-se que há uma atenção especial com a capacitação; no entanto, não há processos estruturados, critérios de elegibilidade ou levantamento de necessidades, seja em benefício da empresa, seja em beneficio do funcionário, o que se reflete na ausência de um planejamento estratégico estruturado. Assim, não há planejamento em termos de capacitação e desenvolvimento, como também não há programação orçamentária para capacitar e desenvolver seus profissionais.

Uma das vertentes desse eixo trata da seleção de pessoal. As empresas pesquisadas responderam que não há um processo formal, nem uma política estruturada de seleção de pessoas.

As ações para atrair e selecionar profissionais para as EEdCs não seguem um fluxo, bem como não são estruturadas a partir de um planejamento de mão de obra. À medida que surge uma vaga, seja em função de um desligamento inesperado, seja por meio de aumento da demanda de trabalho, é que se faz a abertura da vaga junto aos meios de comunicação locais ou a contratação de uma consultoria especializada para que seja efetuada a busca e contratação do profissional.

\section{Comunicação}

De acordo com Ulrich (2003), a adesão aos valores está intrinsecamente ligada à maneira como a empresa comunica, difunde e, principalmente, administra tais valores, uma vez que os valores são visíveis no ambiente organizacional.

Assim, ao analisar as duas vertentes principais na gestão de pessoas desse eixo, percebe-se a ênfase dada ao intercâmbio entre diretores e funcionários por meio de uma comunicação aberta e sincera e a utilização dos mais modernos meios de comunicação, a fim de desenvolver "relacionamentos econômicos, úteis e produtivos".

Em relação a esse eixo, alinhando as falas à observação, percebeu-se que as reuniões com os funcionários para a troca de ideias e exposição de informações sobre a empresa, inclusive financeiras, além de quadros de avisos com informações claras sobre a participação da empresa nos projetos da EdC, são habituais e fazem parte das formas de gestão no polo.

Nos processos de atração de pessoas, levando-se em consideração a segunda vertente - utilização dos mais modernos meios de comunicação - observou-se que as empresas do Polo Spartaco estão estruturadas conforme as práticas realizadas no meio em que ele está inserido.

Os processos são feitos de forma específica a cada necessidade de contratação, mas, de forma geral, utilizam os mesmos meios de comunicação e divulgação de vagas que as empresas da região utilizam. 


\section{Resultados do questionário aplicado}

A fim de complementar os dados obtidos nas entrevistas com os gestores, foi aplicado questionário para que os funcionários respondessem sobre cinco aspectos, destacados a seguir:

\section{1) Aspectos demográficos em relação à religião e participação no Movimento dos Focolares}

- $74 \%$ dos funcionários se declararam católicos enquanto $26 \%$ se declararam evangélicos.

- 70\% afirmaram não ser membros do Movimento dos Focolares.

- A partir das respostas obtidas por meio do questionário, pode-se observar que há uma predominância de funcionários da religião católica, fato que deve estar relacionado à natureza do projeto EdC e suas raízes no cristianismo católico. No entanto, percebe-se que também há funcionários de outras religiões, o que vai ao encontro das informações extraídas da direção das empresas pesquisadas, ao afirmar que não há uma exclusão na contratação por motivação religiosa, mas que há uma tendência a ter mais funcionários católicos devido à ligação das empresas com o Movimento dos Focolares que, em sua gênese, é católico.

\section{2) Aspectos gerais sobre a gestão de pessoas nas empresas de economia de comunhão e a Carta de Princípios da Economia de Comunhão}

- Percebeu-se que, ainda que as políticas de gestão de pessoas não estejam escritas e expostas nas empresas, os funcionários consideram que elas são do conhecimento de todos.

- Em referência à gestão de pessoas e às ações cotidianas como diferencial competitivo nas relações de trabalho, um dos entrevistados acrescentou a seguinte frase: "Aqui somos tratados como gente, os chefes respeitam a gente".

- Percebeu-se que essa relação de proximidade e respeito mútuo é apontada nas falas tanto dos funcionários quanto dos gestores.

\section{3) Avaliação dos funcionários quanto os valores da EdC nas empresas em que trabalham}

- A fim de verificar a presença dos valores que nortearam a Carta de Princípios no cotidiano dos funcionários, apurou-se que, de forma geral, que dois valores se destacam nas referências dos funcionários: harmonia no relacionamento interno; e fidelidade à missão e valores.

- A harmonia no local de trabalho é apontada como o mais importante valor na concepção dos funcionários, sendo este também apontado como o principal valor responsável pela motivação na empresa em trabalham. No entanto, pode-se observar que na visão dos funcionários, o valor de destaque na empresa é a fidelidade à missão e valores.

\section{4) Avaliação dos funcionários quanto à prática dos princípios expressos na Carta de Princípios}

- A fim de se apurar por meio da impressão dos funcionários, a realização das ações que norteiam a Carta de Princípios pelas empresas do Polo Spartaco foram expostos, na sequência original da Carta, os eixos e suas ações, com as seguintes opções de respostas: "sempre", "quase sempre", "raramente", "nunca" e "não tenho opinião".

- Em nenhum dos tópicos o funcionário utilizou as respostas: "raramente", "nunca" ou "não tenho opinião", sendo a resposta mais recorrente "sempre", apontando, assim, que a empresa em que trabalha cumpre "sempre" as ações previstas na Carta de Princípios. 


\section{5) Definição, em uma palavra, que expressa o significado de trabalhar em uma empresas de economia de comunhão}

- No último tópico do questionário, foi solicitado ao funcionário que utilizasse uma palavra para descrever o que significa para ele trabalhar em uma EEdC. Palavras como fraternidade, respeito, dignidade, realização, reciprocidade, alegria, fé, solidariedade foram as mais utilizadas, sendo as duas primeiras as mais recorrentes.

- Analisando as respostas obtidas, seja por meio das respostas diretas dos entrevistados, seja por meio dos questionários, conversas informais ou por meio da observação em campo, pode-se perceber que é visível o alinhamento entre as falas dos gestores e a prática estabelecida nas relações de trabalho, bem como na Carta de Princípios que rege as EEdCs.

\section{Conclusões}

A partir dos dados pesquisados, no que se refere às práticas de gestão de pessoas nas empresas vinculadas à EdC, percebe-se que o discurso, de fato, coaduna a prática.

Enquanto as empresas em geral, que não seguem os princípios da EdC, esforçam-se para criar estratégias capazes de engajar os funcionários com as metas organizacionais, as EEdCs do Polo Spartaco apresentam esse engajamento por meio de suas práticas de gestão de pessoas, auxiliadas pela Associação de Funcionários, que atua como interlocutora entre as empresas e seus funcionários.

A atuação da associação pode ser considerada estratégica para as empresas do Polo Spartaco, pois suas empresas não possuem estruturas que comportem um setor específico de gestão de pessoas em cada empresa, sendo a atuação da associação, ao se colocar como interlocutora entre as empresas e seus funcionários fomentando as relações de trabalho, a saúde e o bem-estar social e cultural dos funcionários - um diferencial estratégico para a gestão de pessoas no polo.

A partir da análise do papel da associação e sua inserção nas práticas voltadas aos funcionários, percebeu-se que sua atuação incorpora com sucesso o proposto pelas práticas e princípios da gestão estratégica de pessoas, onde o ser humano deixa de ser apenas uma peça, parte de uma engrenagem, para ser o principal ativo das organizações.

Ao intermediar os desejos e anseios dos funcionários com as empresas e trabalhar tais demandas de forma clara e objetiva, a associação produz efeitos estruturais nas práticas de gestão de pessoas no Polo Spartaco, que devem ser considerados diferencial competitivo nas relações de trabalho.

Outra característica que facilita a atuação da associação e das EEdCs do Polo Spartaco é a própria cultura da comunhão e os princípios de gestão bem definidos pela Carta de Princípios, que fazem com que as empresas, apesar de ter a finalidade do lucro e atuar no mesmo cenário competitivo que as demais empresas que não partilham de tais princípios, não pautem suas estratégias unicamente na obtenção de lucro, mas, também, na partilha, onde os fornecedores, concorrentes e sociedade fazem parte do equilíbrio econômico.

Percebeu-se que os funcionários compreendem a associação como parte da empresa e não como uma instituição independente, o que reforça seu papel estratégico se comparada a um setor específico de gestão de pessoas.

$\mathrm{Na}$ atualidade, temas como o capital social, o capital humano, a responsabilidade das empresas com a sociedade e com o meio ambiente fazem parte das estratégias das empresas em geral e tem representado fonte de motivação e retenção de funcionários. A partir dos dados obtidos, concluiu-se que os valores que sustentam as EEdCs, por si, já representam fontes de atração e retenção de seus funcionários. 
Concluiu-se, ainda, que as práticas de gestão de pessoas observadas no contexto da pesquisa norteiam outras considerações correspondentes ao discurso da EdC e suas práticas em relação ao ser humano e às relações de trabalho.

Ora, se as práticas de gestão de pessoas visam à produtividade, ao engajamento, à participação, ao espírito de corpo (pertencimento), à consolidação de valores, percebeu-se que isso é o que, de fato, extrai-se da experiência vivida no Polo Spartaco. Elas estão presentes, ainda que de forma pouco estruturada, pouco pretensiosa e pouco científica, mas pautadas em pilares tidos como fundamentais em um ambiente corporativo contemporâneo: coerência, transparência e consistência.

Assim, concluiu-se que o que, de fato, importa nos processos de gestão de pessoas não é apenas ter um setor estruturado, discurso moderno e políticas bem definidas, mas a coerência e a consistência da prática com o discurso, daquilo que se propõe ao colocar o funcionário como centro da empresa, não o capital, da transparência nas relações de trabalho, e do respeito ao ser humano no âmbito organizacional, valores estes que, observados pela visão dos funcionários do Polo Spartaco, constituem um diferencial competitivo nas EEdCs.

\section{Referências}

BARAÚNA, M. (Coord.). Economia de comunhão e movimento econômico: desenvolvimento e perspectivas. São Paulo: Cidade Nova, 1999.

BENTO XVI. Encíclica Caritas in Veritate. São Paulo: Paulus, 2009.

BRUNI, L. (Org.). Economia de comunhão: uma cultura em várias dimensões. São Paulo: Cidade Nova, 2002.

BUBER. M. Sobre comunidade. São Paulo: Perspectiva, 1987.

BURCKART, H. Desenvolvimento sustentável e gerenciamento empresarial: elementos para um novo paradigma de gestão. In: BRUNI, L. (Org.). Economia de comunhão: uma cultura em várias dimensões. São Paulo: Cidade Nova, 2002.

CALLIARI, G. O projeto de economia de comunhão: acenos sobre a origem, o desenvolvimento e algumas repercussões. In: BUREAU INTERNACIONAL DA ECONOMIA E TRABALHO, 1999. Anais... São Paulo: Cidade Nova, 2000. p.1-168.

CARVALHO, M. L.; GUARESCHI, P. Economia de comunhão: responsabilidade social, ideologia e representações sociais. Psicologia: Ciência e Profissão, v. 29, n. 1, p. 88-101, 2009.

DAVEL E.; VERGARA, S. C. (Org.). Gestão com pessoas e subjetividade. São Paulo: Atlas, 2001.

DELGADO, J.; GUTIERREZ J. Métodos y técnicas cualitativos de investigación en ciencias sociales. Madrid: Sintesis, 1995.

DRUCKER, P. F. Administrando em tempos de grandes mudanças. São Paulo: Pioneira, 2001.

DUTRA, J. S. Gestão de pessoas com base em competências. 3. ed. São Paulo: Gente, 2001.

Gestão de pessoas: modelo, processos, tendências e perspectivas. São Paulo: Atlas, 2002.

ECONOMIA DE COMUNHÃO - EDC. Relatório EdC 2009/2010. Disponível em: <http://www.edconline.org/br/quem-somos/partilha-dos-lucros/1312-rapporto-edc-2009-2010.html>. Acesso em: 10 maio 2011. 
2012.

O que é EdC. Disponível em: <http://www.edc-online.org/br/quem-somos.html>. Acesso em: 31 out.

FISCHER, A. L. O conceito de modelo de gestão de pessoas: modismo e realidade em gestão de recursos humanos nas empresas brasileiras. In: DUTRA, J. S. Gestão por competências. 3. ed. São Paulo: Gente, 2001.

FLEURY, A.; FLEURY, M. T. L. Estratégias empresariais e formação de competências: um quebra-cabeça caleidoscópico da indústria brasileira. 3. ed. São Paulo: Atlas, 2004.

GUERREIRO RAMOS, A. A redução sociológica: introdução ao estudo da razão sociológica. Rio de Janeiro: Iseb, 1958.

GUI, B.; BRUNI, L. A economia de comunhão em quatro palavras. Economia de Comunhão: uma Nova Cultura, v. 13, p. 6-8, 2001.

KAPLAN, R. S.; NORTON, D. P. A estratégia em ação. Rio de Janeiro: Campus, 1997.

LEIBHOLZ, H. Entrevista com Rodolfo Leibholz. Suplemento da Revista Cidade Nova, n. 17, v. 9, n. 2, 2003.

LEITÃO, S. P.; SPINELLI, R. A. Economia de comunhão no Brasil: a produção acadêmica em administração de 1991 a 2006. RAP, v. 42, n. 3, p. 451-469, maio/jun. 2008.

LINARD, K. T. Economy of communion: systemic factors in the rise of a new entrepreneurship. Systems Research and Behavioral Science, n. 20, p. 163-175, 2003.

LUBICH, C. Economia de comunhão, uma nova cultura: um terço, um terço e um terço. Revista Cidade Nova, n. 3, p. 3, 1996.

. O movimento dos focolares e a economia de comunhão. In: BUREAU INTERNACIONAL DA ECONOMIA E TRABALHO, 1999. Anais... São Paulo: Cidade Nova, 2000. p. 9-19.

. Os problemas de desenvolvimento das empresas de "motivação ideal". In: BRUNI, L. (Org.). Economia de comunhão: uma cultura em várias dimensões. São Paulo: Cidade Nova, 2002. p. 12-19.

MARRAS, J. P. Administração de recursos humanos. 3. ed. São Paulo: Futura, 2000.

MORGAN, G. Imagens da organização. São Paulo: Atlas, 1996.

NARDI, H. C. Ética e trabalho: do código moral à reflexão ética no contexto das transformações contemporâneas. In: BITENCOURT, C. et al. Gestão contemporânea de pessoas. Porto Alegre: Artmed, 2004. p. 454-467.

OLABUÉNAGA, J. I. Metodologia de la investigación cualitativa. Bilbao: Universidad de Deusto, 1999.

OLIVEIRA, S. Tratado de metodologia científica: projetos de pesquisas, TGI, TCC, monografias, dissertações e teses. São Paulo: Pioneira, 1997.

PINTO, M. C. S.; LEITÃO, S. P. Economia de comunhão, empresas para um capitalismo transformado. Rio de Janeiro: Ed. FGV, 2006.

PORTER, M. E. Vantagem competitiva: criando e sustentando um desempenho superior. Rio de Janeiro: Campus, 1989.

QUARTANA, P. Economia de comunhão no pensamento de Chiara Lubich. In: QUARTANA, P. et al. (Org.). Economia de comunhão: propostas e reflexões para uma cultura da partilha, a cultura do dar. São Paulo: Cidade Nova, 1992. 
ROBBINS, S. P. Mudança organizacional e administração do estresse. In: Comportamento organizacional. Rio de Janeiro: LTC, 1999. p. 421-446.

SERAFIM, M. C. A ética no espaço de produção: contribuições da economia de comunhão. 2001 . 146 p. Dissertação (Mestrado em Engenharia de Produção) - Universidade Federal de Santa Catarina, Florianópolis, 2001.

TAMAYO, A. Valores organizacionais. In: TAMAYO, A.; BORGES-ANDRADE J.; CODO, W. Trabalho, organizações e cultura. São Paulo: Cooperativa de Autores Associados, 1996. p. 175-193.

.; BORGES, L. O. Valores del trabajo y valores de las organizaciones. In: ROS M.; GOUVEIA V. (Org.) Psicología social de los valores. Madrid: Biblioteca Nueva, 2001. p. 325-352.

;; GONDIM, M. G. C. Escala de valores organizacionais. RAUSP, v. 31, n. 2, p. 62-72, 1996.

ULRICH, D. Os campeões de recursos humanos: inovando para obter os melhores resultados. São Paulo: Futura, 2003.

VANDELEENE, M. C. (Org.). Ideal e luz: pensamento, espiritualidade. São Paulo: Cidade Nova, 2003.

VIEIRA, P. R.; CARDOSO, A. S. R. Construção, desconstrução e reconstrução de sistemas de valores nas organizações. Cadernos EBAPE.BR, v. 1, n. 2, p. 1-11, dez. 2003.

YIN, R. K. Estudo de caso: planejamento e métodos. 3. ed. Porto Alegre: Bookman, 2005. 